\title{
Disseminated Thrombosis in COVID-19 Cases: The Role of Early Antithrombotic Treatments?
}

\author{
Jasem Mohammed Alhashmi ${ }^{a, b}$ Ashraf M. Elhoufic Eman Elhatou ${ }^{a}$ \\ Mahmood Ghanaim ${ }^{\text {d }}$ \\ ${ }^{a}$ Cardiology Department, Dubai Hospital, Dubai Health Authority, Dubai, UAE; b Warsan Hospitality Care Center, \\ Dubai, UAE; 'Intensive Care Section, Dubai Hospital, Dubai Health Authority, Dubai, UAE; dEmergency Section, \\ Dubai Hospital, Dubai Health Authority, Dubai, UAE
}

\section{Keywords}

COVID-19 · New coronavirus · Coagulation · Thrombosis ·

Dubai · United Arab Emirates

\section{Abstract}

Many newly published articles have focused on the association between COVID-19 and thrombogenicity. Indeed, it has become a frequently observed phenomena. In this study, we report on a 45-year-old man with a COVID-19-positive test. His dramatic progression started 5 days after admission. He developed a right ventricular (RV) thrombus (rare condition) and multiple brain sites infarction. We discuss this phenomena by showing the extent to which the thrombosis can take place, the possible relation between inflammatory, D-dimer and case progression and suggest a treatment approach particularly in cases with multiple thrombogenicity organ involvement.

(c) 2020 The Author(s) Published by S. Karger AG, Basel
(C) 2020 The Author(s)

Published by S. Karger AG, Basel

This article is licensed under the Creative Commons AttributionNonCommercial-NoDerivatives 4.0 International License (CC BYNC-ND) (http://www.karger.com/Services/OpenAccessLicense) Usage and distribution for commercial purposes as well as any distribution of modified material requires written permission.

\section{Introduction}

Systemic coagulation activation and thrombotic complications are a well observed phenomena in COVID-19 cases. Thrombus can occur in heart, lung and brain and at peripheries. We report a unique case of COVID-19 which developed multiple thromboses at different organ sites.

\section{Case Presentation}

A 45-year-old man presented to the emergency department at the Dubai Hospital on May 1, 2020 at 1:20 p.m. with a 1-day history of fever, cough, sore throat and shortness of breath. His vital signs are shown in Table 1.

\section{Physical Exam}

He appears well developed and well nourished. Effort breathing with normal breath sounds. Tachypnea noted, no respiratory distress, and heart auscultation revealed tachycardia with no added sound or murmur.

Jasem Mohammed Alhashmi

Consultant and Head of Cardiology Department

Dubai Hospital, Dubai Health Authority

Al Khaleej Street, Al Baraha, PO Box 7272 Dubai (UAE)

jmalhashmi@dha.gov.ae 
Table 1. Initial vital signs of the patient recorded at the AE department

\begin{tabular}{llllllll}
\hline Temperature & Pulse rate & Resp & BP & Height & Weight & BMI & SpO2 \\
\hline $40.2^{\circ} \mathrm{C}\left(104.4^{\circ} \mathrm{F}\right)$ & 128 & 44 & $128 / 70$ & $166 \mathrm{~cm}(65.35 ”)$ & $77 \mathrm{~kg}$ & $27.94 \mathrm{~kg} / \mathrm{m}^{2}$ & $95 \%$ \\
\hline
\end{tabular}

Table 2. Initially started medications for the patient at the AE department

\begin{tabular}{lcll}
\hline Medication & $\begin{array}{l}\text { Dose/ } \\
\text { interval }\end{array}$ & Length of treatment & Route \\
\hline Hydrochloroquine & $300 \mathrm{mg} / \mathrm{b}$. i.d. & 7 days & Oral \\
Azithromycin & $500 \mathrm{mg} /$ daily & 3 days & Oral \\
FAVIPIRAVIR & $1,600 / \mathrm{b}$. i.d. & 2 days & Oral \\
cefTRIAXone & $2 \mathrm{mg} / \mathrm{b} . i . d$. & 7 days & Intravenous \\
Enoxeparin & $40 \mathrm{mg}$ daily & 5 days & SC \\
\hline
\end{tabular}

Table 3. The progression of the patient's lab markers is shown

\begin{tabular}{|c|c|c|c|c|c|c|c|c|c|}
\hline Test & Ref. range and units & $1 / 5$ & $5 / 5$ & $7 / 5$ & $8 / 5$ & $9 / 5$ & $10 / 5$ & $11 / 5$ & $12 / 5$ \\
\hline Procal & $<0.05 \mathrm{ng} / \mathrm{mL}$ & 0.72 & 0.58 & 0.31 & 0.79 & 33.90 & 23.00 & 15.20 & 17.00 \\
\hline CRP & $<5.0 \mathrm{mg} / \mathrm{L}$ & 194.9 & 225.8 & 101.6 & 274.9 & 438.2 & 532.2 & 383.6 & 274.0 \\
\hline Dimer & $<0.5 \mu \mathrm{g} / \mathrm{mL}$ FEU & 0.56 & & 23.55 & 21.83 & 5.33 & 3.44 & 3.76 & 4.32 \\
\hline Plat & $150-41010: 3 / \mu \mathrm{L}$ & 287 & 383 & 231 & 219 & 228 & & 173 & 187 \\
\hline WBC & $3.6-11.010: 3 / \mu \mathrm{L}$ & 13.1 & 5.8 & 11.9 & 11.5 & 17.2 & & 18.8 & 10.9 \\
\hline
\end{tabular}

CRP, C-Reactive protein; Procal, procalcitonin; Plat, platelets count; Hb, hemoglobin.

The patient tested positive for COVID-19. He was managed in the AE COVID-19 isolation unit. In addition to $10-15 \mathrm{~L} / \mathrm{min}$ oxygen mask, paracetamol (IV tablets) and IV fluid, he received medications, for details see Table 2. Unfortunately, the patient experienced dramatic progression and worsening of his condition.

Table 3 shows the progression of his lab markers. CXRs (Fig. 1-4) series taken as the patient condition progressed with the COVID-19 managements.

He became more agitated and restless despite $\mathrm{O} 2$ saturation ranging between 95 and $98 \%$ on $15 \mathrm{~L} / \mathrm{min}$ of oxygen. On May 6, 2020, the patient complained of weakness in his face since the morning and drooling of saliva. The patient was unable to talk properly, complaining of difficulty in talking with hoarseness of voice. Signs of UMN involvement of facial nerve were noted. Tone and power were normal in his upper arms. An urgent brain CT scan was ordered and reported the following: cortical and subcortical inhomogeneous hy- podensities involving bilateral frontal, temporal bilateral cerebellar lobes, suggestive of recent ischemic insult (Fig. 5).

The patient was loaded with aspirin $300 \mathrm{mg}$ and daily $75 \mathrm{mg}$ enoxaparin, shifted from prophylactic dose into full therapeutic doses of $80 \mathrm{mg}$ twice daily. Bedside echocardiography done on May 7, 2020 showed the following: preserved cardiac chamber dimensions, LVEF $60 \%$, normal flow across the heart valves. There were relatively large mobile thrombus seen attached to the anterior cuspid of tricuspid valve in the right ventricular inflow subcostal view (Fig. 6a, b).

The patient developed respiratory failure and desaturating SpO2 less than 90\%. ABG: $\mathrm{PH} 7.4, \mathrm{PCO} 2$ 72.6, $\mathrm{HCO} 3$ 28.7, $\mathrm{SO} 2$ 94.2. He was electively intubated on May 7, 2020. His general condition worsened. He developed brady asystole, resuscitated as per ACLS protocol, but the trials were not successful. His death was declared on May $11,2020$. 
1

Fig. 1. May 1, 2020: Mid and lower lung bilateral air space opacification, with a rounded configuration and peripheral predominance. Heart appears normal in size. No pleural effusion or pneumothorax.

Fig. 2. May 5, 2020: Diffuse air space opacities in both lungs suggesting pneumonic infiltrate with increase in size compared to the previous examination seen in Figure 1. Heart size is mildly enlarged.

Fig. 3. May 7, 2020: Chest X-ray: supine portable in comparison to May 6, 2020 supine portable, there is mild regression of the bilateral typical pulmonary consultations. Right-sided catheter up in SVC.

Fig. 4. May 10, 2020: Increasing diffuse right lung infiltrates. Persisting left lung infiltrates. Cardiac size appears to be stable.

Fig. 5. CT-brain, cortical and subcortical inhomogeneous hypodensities involving bilateral frontal (a) and temporal bilateral (b) cerebellar lobes suggestive of recent ischemic insult.

3

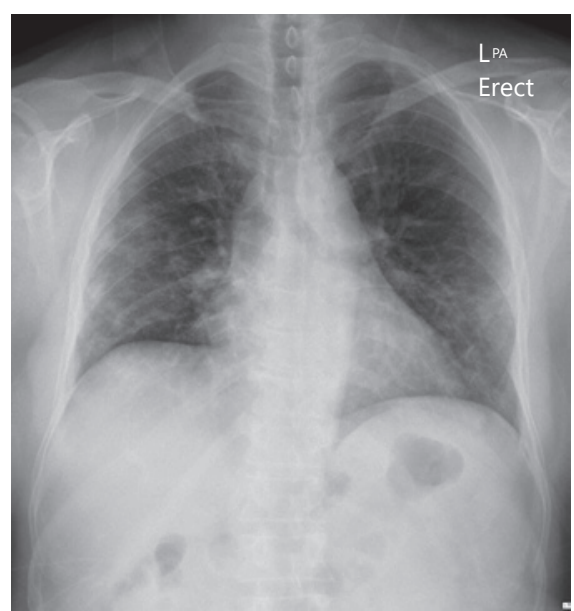

2

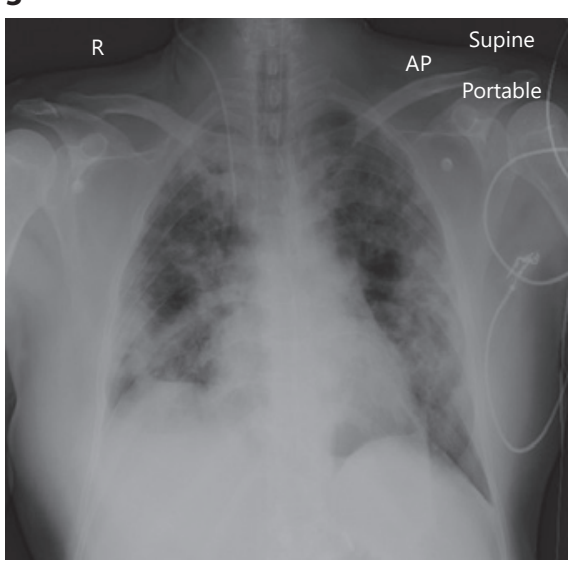

4
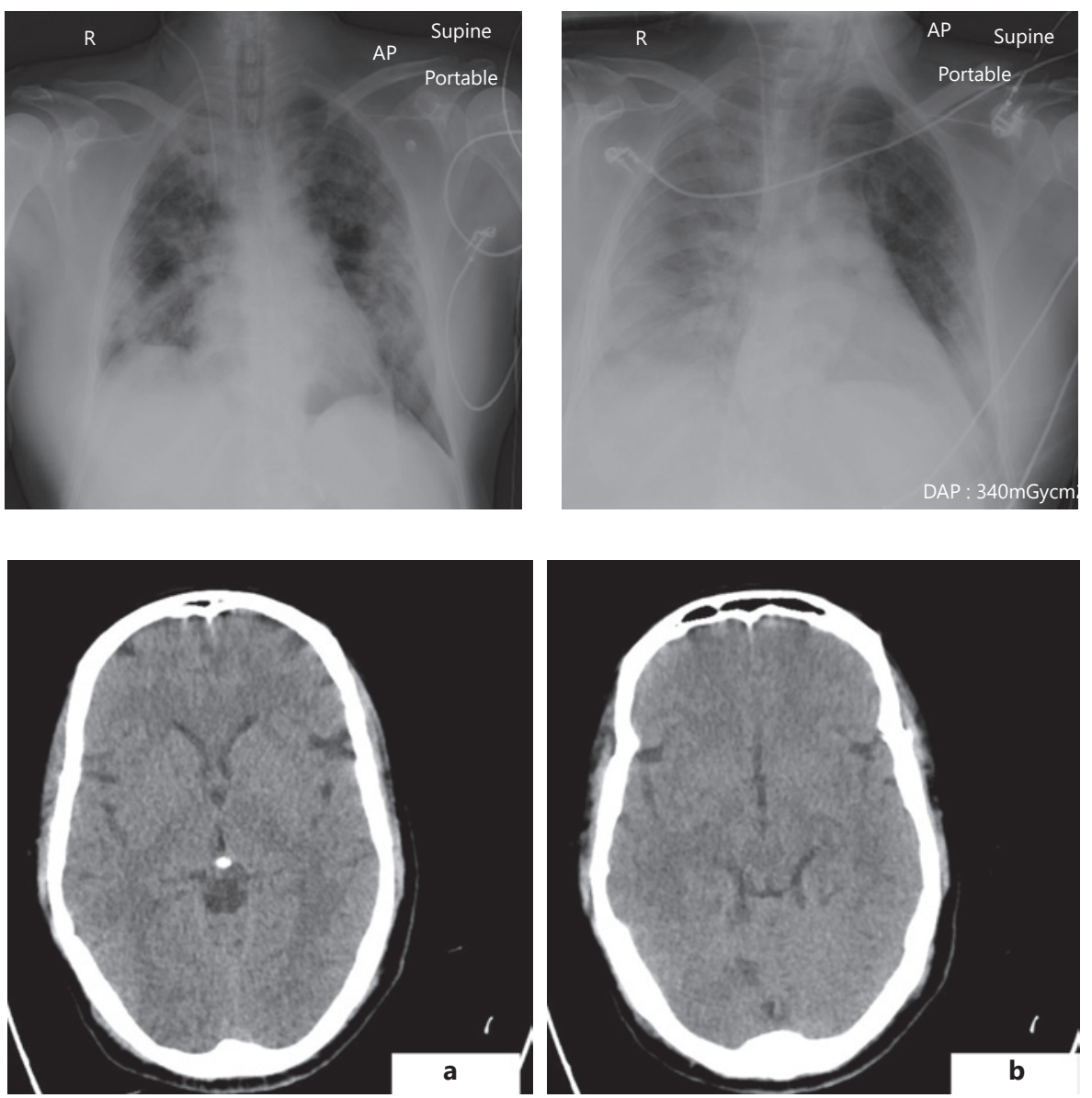

\section{Discussion}

The reported case showed a disseminated hypercoagulable status. The case has low risk factors for developing thromboembolic phenomena. In the era of the COVID-19 pandemic outbreak, several pathological entities have been proposed by different researchers. Activation of the coagulation system has been observed in many cases. Preliminary data show that in patients with severe $\mathrm{CO}$ VID-19, anticoagulant therapy appears to be associated with lower mortality in the subpopulation meeting sepsis-induced coagulopathy criteria or with markedly ele- 
Fig. 6. a, b Large mobile thrombus seen attached to the anterior cuspid of tricuspid valve in the right ventricular inflow.
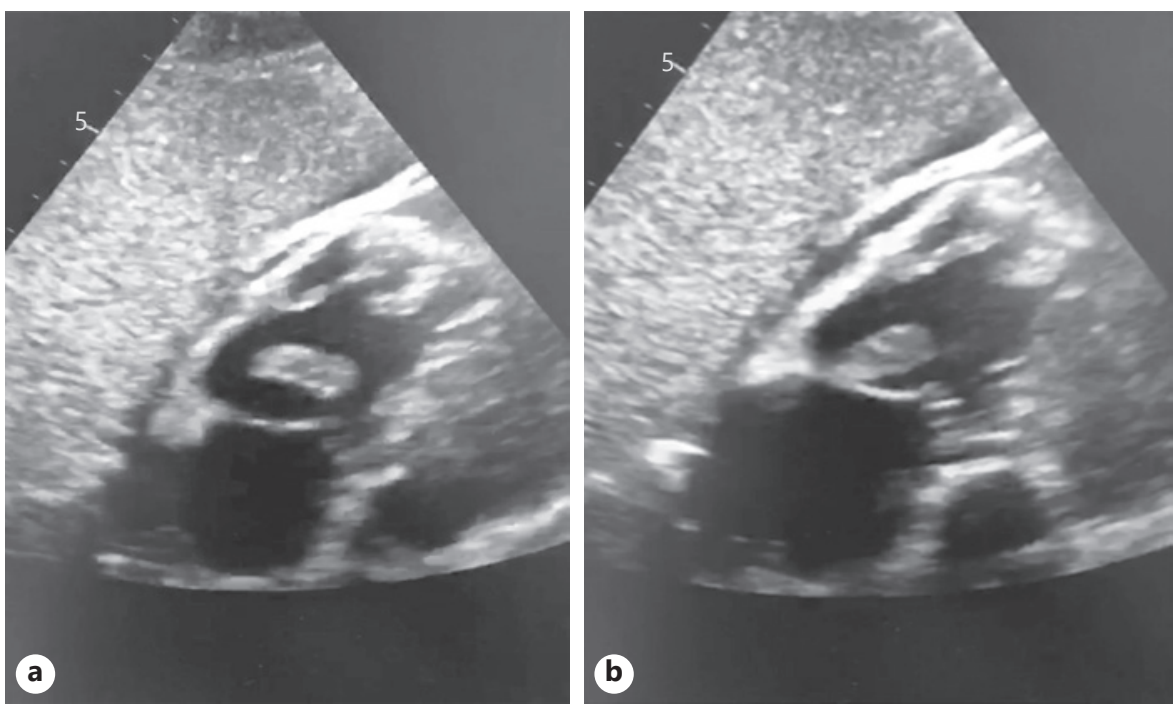

vated D-dimer $[1,2]$. Reports of sepsis, DIC high D-dimer, raised inflammatory CRP, and procalcitonin $[3,4]$ can lead to the conclusion that the hypercoagulability criteria in Virchow's triad is the leading thrombogenic factor in COVID-19.

Development of cardiac thrombus (RV) is a rare finding. Right ventricular thrombus formation is a potential complication of ARVC with impaired right ventricular function [5]. As in LV thrombus of formation, the conventional treatment is to receive a therapeutic dose of heparin (either conventional or LMWH). In acutely formed right ventricular thrombus as in this case, we consulted a neurologist for further management with dose of enoxaparin in the presence of acute CVA. He suggested that we should start on a prophylactic dose of $40 \mathrm{mg}$ s.c. b.i.d., repeat CT scan after $24 \mathrm{~h}$, and if no progression occurs, then to consider a full therapeutic dose of enoxaparin.

Right heart thrombus (RHT) typically represent mobilized deep vein thromboses that have become lodged temporarily in the right atrium or right ventricular $[6,7]$. This can add more to our understanding of the disseminated nature of thrombogenicity of COVID-19 disease. Although in this case DVT was not looked at even with the presence of high lab results of D-dimer (Table 3), we should highly suspect DVT in high D-dimer and perhaps start a therapeutic dose of heparin as soon as possible to avoid further embolic phenomena.

Furthermore, the natural history of pulmonary embolism (PE) is incompletely characterized because most episodes of $\mathrm{PE}$ go undetected [8]. In this case with an appropriate ventilation setting and oxygenation, we should not ignore the pulmonary embolic phenomena which can happen and pass undetected clinically perhaps due to small emboli showers.

The development of cerebrovascular accident (CVA) has dramatic clinical consequences in a COVID-19 patient and a huge impact on medical services. It seems to carry a very high mortality rate. In our hospital, COVID-19 patients who developed CVA have $100 \%$ mortality rate.

\section{Conclusion}

COVID-19 cases can develop hypercoagulability status. This hypercoagulability and involvement of major organs, like the heart and brain, can have a significant mortality outcome. Introduction of therapeutic antithrombotic treatments such as heparin, antiplatelet and or new oral anticoagulants for these patients as much earlier as possible in the disease may reduce the severity of the disease outcome. Further studies with controlled trials for medical evidence are needed.

\section{Statement of Ethics}

According to the Dubai Scientific Research Ethics Committee (DSREC), Dubai Health Authority, no consent from the patient is needed to publish this case report (Ref. DSREC-GL12-2020, of October 15, 2020).

\section{Conflict of Interest Statement}

The authors have no conflicts of interest to disclose. 


\section{Funding Sources}

No funding was received.

\section{References}

1 Kollias A, Kyriakoulis KG, Dimakakos E, Poulakou G, Stergiou GS, Syrigos K. Thromboembolic risk and anticoagulant therapy in COVID-19 patients: emerging evidence and call for action. Br J Haematol. 2020 Jun; 189(5):846-7.

2 Tang N, Bai H, Chen X, Gong J, Li D, Sun Z. Anticoagulant treatment is associated with decreased mortality in severe coronavirus disease 2019 patients with coagulopathy. J Thromb Haemost. 2020 May;18(5):1094-9.

3 Lillicrap D. Disseminated intravascular coagulation in patients with 2019 -nCoV pneumonia. J Thromb Haemost. 2020 Apr;18(4):78687. doi: https://doi.org/10.1111/jth.14781. Epub 2020 Mar 24. J Thromb Haemost. 2020.

\section{Author Contributions}

All authors contributed equally.
4 Helms J, Tacquard C, Severac F, Leonard-Lorant I, Ohana M, Delabranche X, Merdji H, Clere-Jehl R, Schenck M, Fagot Gandet F, Fafi-Kremer S, Castelain V, Schneider F, Grunebaum L, Anglés-Cano E, Sattler L, Mertes PM, Meziani F; CRICS TRIGGERSEP Group (Clinical Research in Intensive Care and Sepsis Trial Group for Global Evaluation and Research in Sepsis). High Risk of Thrombosis in Patients With Severe SARS-CoV-2 Infection: A Multicenter Prospective Cohort Study. Intensive Care Med. 2020 Jun;46(6): 1089-98. doi: https://doi.org/10.1007/ s00134-020-06062-x. Epub 2020 May 4.

5 Akdis D, Chen K, Saguner AM, Stämpfli SF, Chen X, Chen L, et al. Clinical Characteristics of Patients with a Right Ventricular Thrombus in Arrhythmogenic Right Ventricular Cardiomyopathy. Thromb Haemost. 2019 Aug;119(8):1373-8.

6 Kronik G; European Working Group on Echocardiography. The European Cooperative Study on the clinical significance of right heart thrombi. Eur Heart J. 1989 Dec;10(12): 1046-59.

7 Chartier L, Béra J, Delomez M, Asseman P, Beregi JP, Bauchart JJ, et al. Free-floating thrombi in the right heart: diagnosis, management, and prognostic indexes in 38 consecutive patients. Circulation. 1999 Jun;99(21):2779-83.

8 Olin JW. Pulmonary embolism. Rev Cardiovasc Med. 2002;3 Suppl 2:S68-75. 